\title{
Cómo evitar pérdidas
en el secado y en la cocción
}

C. N. WALLEY

The British Clayworker, mayo 1971, paig. 22

Una vez concluido el proceso de cocción, cada ladrillo desechado representa una pérdida financiera equivalente al costo de un ladrillo de primera calidad. El término "desechado" debe abarcar también a los ladrillos defectuosos y a los de calidad inferior, en mayor o menor grado. Por ejemplo dos ladrillos de baja calidad vendidos a mitad de precio puede considerarse como un ladrillo de pérdida.

El factor económico es el criterio de valoración. Por ejemplo, y de una forma aproximada, podemos tener un costo para los ladrillos de 3.300 pesetas el millar, un precio para el combustible de 1.160 pesetas la tonelada, requiriéndose $254 \mathrm{~kg}$ para 1.000 ladrillos. En consecuencia, el costo del combustible es de 288 pesetas para hacer 1.000 ladrillos; es decir, menos del $9 \%$ del valor del ladrillo. Por ejemplo: un $1 \%$ de desperdicio corresponde a un $11 \%$ del costo del combustible. Un $5 \%$ de desperdicio significa un $55 \%$ del costo del combustible y un $9 \%$ de pérdidas equivale al costo total del combustible.

Tales sencillos cálculos nos conducen a lo que se entiende por eficiencia cerámica, en comparación con la eficiencia del combustible, recordándose que la eficiencia del combustible o el costo del mismo no puede ser considerado aisladamente. Un combustible de alto precio puede resultar más económico si con ello se reducen las pérdidas originadas, por ejemplo, por las cenizas y escorias, o sobrecalentamientos locales; y la economía de una cocción más rápida o un encañado más denso puede elevarse por una degradación creciente. Respecto al secado pueden establecerse las mismas consideraciones. Cada fábrica tiene sus propios problemas, y las causas de tener "desperdicios" son muy variadas. En este aspecto es del máximo interés considerar los aspectos fundamentales del secado y la cocción, nos conducirán a un mayor conocimiento y ayudarnos a llegar a soluciones específicas.

\section{S E C A D O}

Frecuentemente la causa principal del calor desperdiciado proviene no de la cocción en sí, sino del secado, bien en el secadero o bien en el horno. Nunca dos arcillas tienen exactamente las mismas características de secado, y ni que decir tiene que, en la fabricación de ladrillos se utiliza una amplia variedad de arcillas. Sin embargo, todas las arcillas muestran el mismo comportamiento general en el secado. 


\section{El secado observado al microscopio}

La arcilla de un ladrillo recién moldeado (fig. 1-a) es una mezcla de partículas sólidas rodeadas y separadas por películas de agua, siendo también la superficie del ladrillo una delgada y continua película de agua. La evaporación desde su superficie se produce de una manera exactamente igual que en un estanque de agua, siendo reemplazada por el agua que afluye de entre las partículas interiores. En consecuencia, las partículas se aproximan unas a otras y el ladrillo se retrae.
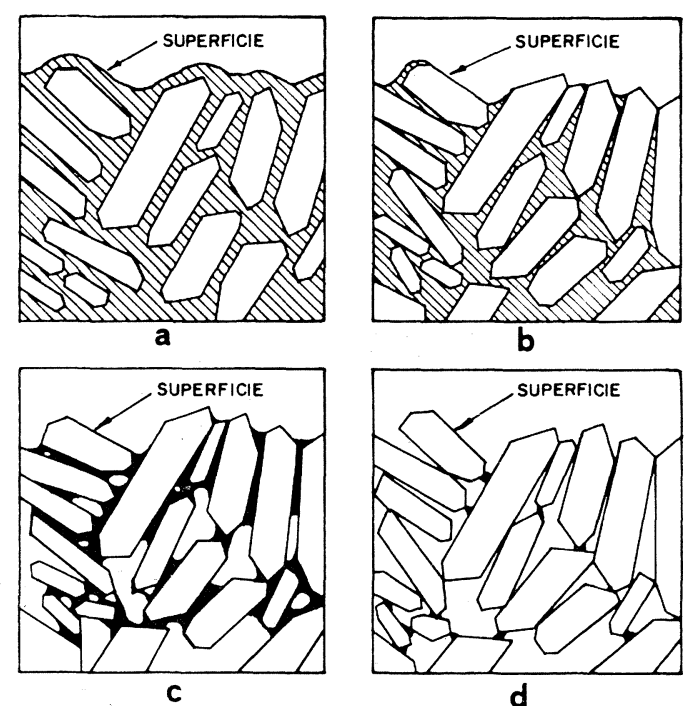

Fig. 1.-Secciones ampliadas de la arcilla en las diversas etapas.

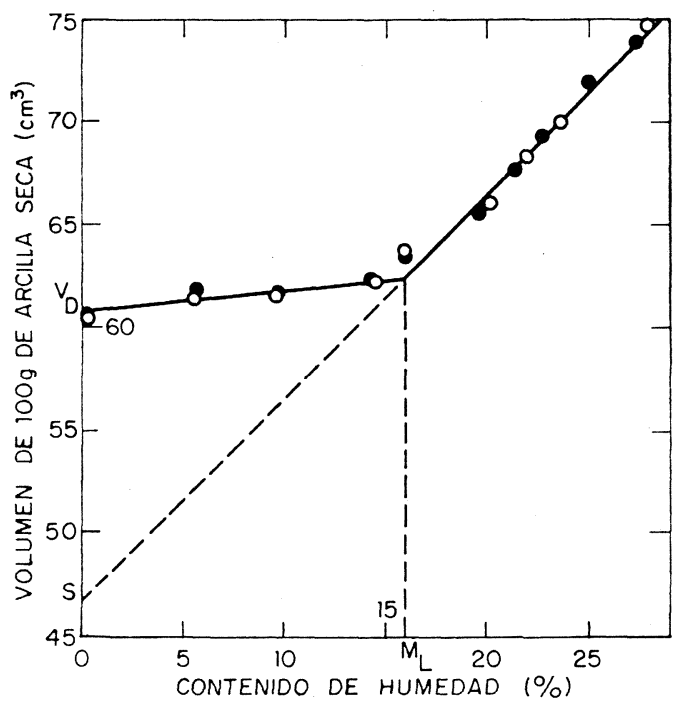

Fig. 2.-Curva de retracción del volumen.

Eventualmente, las partículas entran en contacto (fig. 1-b) y la retracción casi deja de producirse. Se suele llamar a esto "punto correoso". La película de agua superficial se seca, dando lugar a un cambio de color, diciéndose entonces que los ladrillos están "secos en blanco". El resto del agua se evapora más despacio, quedando aire en los poros (fig. 1-c). El agua que se elimina en último lugar es la interpuesta entre las partículas, llevándose a cabo esto más en el horno que en el secadero (fig. 1-d). La disminución de volumen al pasar de la etapa (a) a la (b) es igual al volumen de agua evaporada (fig. 2).

Durante la primera etapa del secado, cuando el agua se está evaporando únicamente en la superficie, el contenido de humedad en la proximidad de la superficie llega a ser menor que en el centro y, por tanto, es esta diferencia la que origina que el agua fluya a la superficie para que se evapore (fig. 3). Las arcillas plásticas de grano muy fino, como por ejemplo la arcilla de Londres, tienen una elevada resistencia a que el agua fluya y, por consiguiente, durante el secado se produce un elevado gradiente de humedad.

Esta diferencia en el contenido de humedad implica que en esta etapa la parte externa se retrae más que la central y, en consecuencia, se encuentra bajo tensiones de tracción. Está más propensa a la fisuración cuanto mayor es esta diferencia, es decir, cuanto más rápido sea el secado. Estas fisuras surgirán en la superficie, particularmente en las aristas $\mathrm{y}$ vértices. 
Después de que la superficie ha acabado de contraerse, la parte central se encontrará todavía con un contenido de humedad de "cuero duro" y tenderá a contraerse; esto se evitará al convertirse en una cáscara dura. La parte central entonces se encuentra bajo tensiones y pueden originarse fisuras al extenderse desde el centro hacia la superficie.

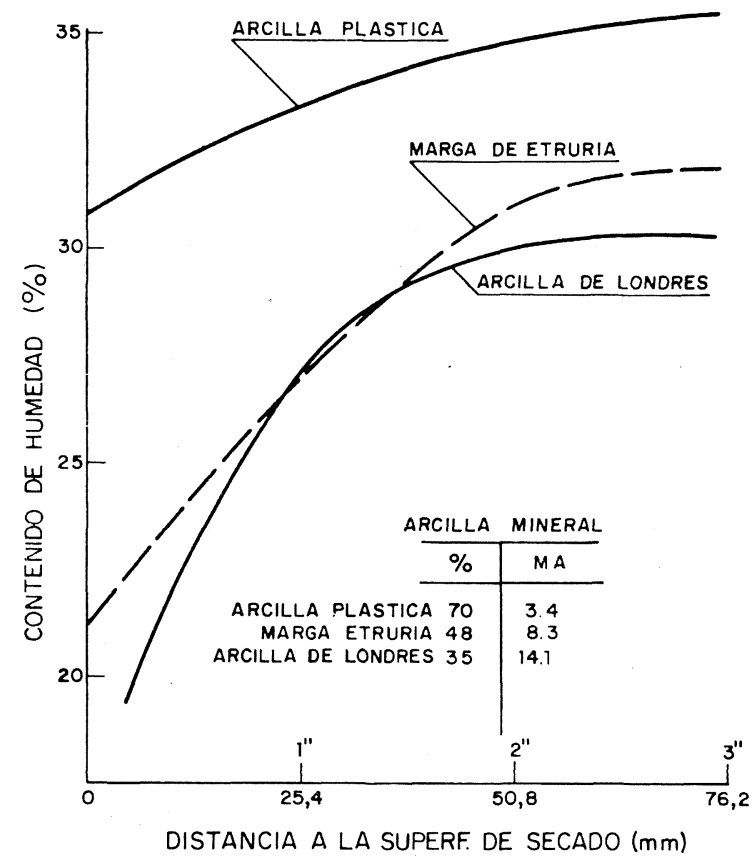

Fig. 3.-Curva de distribución de humedad.

El secado, por consiguiente, siempre da lugar a tensiones; pero cuanto más rápido es el secado, tanto mayores son las tensiones, y los agrietamientos se producen en cuanto se sobrepasa la resistencia del cuerpo. Pueden producirse resistencias más bajas por cambios en la mezcla de arcilla, por meteorización, molienda y, en general, en la preparación. El proceso de moldeo, en particular, da lugar a planos de debilitamiento, que puede dar lugar a material de desecho durante el secado y la cocción. En condiciones ideales, el tiempo de secado puede reducirse a 8 horas con cierta seguridad y la mayor parte de los ladrillos pueden ser secados en 24 horas. En la práctica, sin embargo, se requiere un tiempo más prolongado, ya que las condiciones no son las ideales $y$, también, porque hay dificultades para cocer los ladrillos que se encuentran en el centro del encañado y otros, en cambio, están en la parte exterior.

El secado normalmente se realiza haciendo pasar aire caliente por los ladrillos húmedos. El calor del aire proporciona el requerido para la evaporación, o sea, el calor latente, y permite al aire aumentar su capacidad de fijación de vapor de agua arrastrándolo a la atmósfera (fig. 4).

Fig. 4.-Condiciones en una superficie húmeda durante el secado.

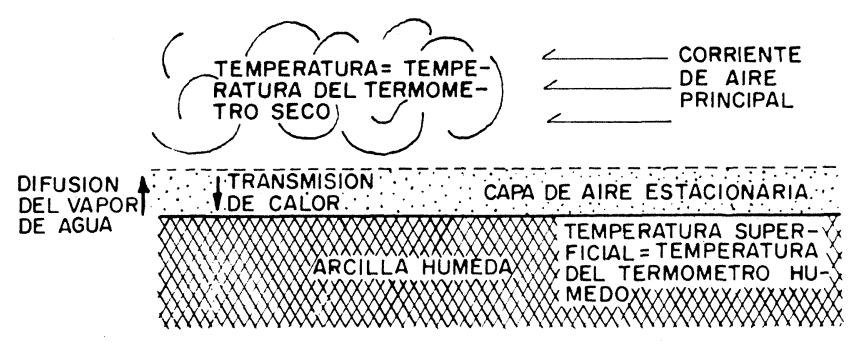

Siempre hay una delgada capa de aire estanco en contacto con la superficie húmeda, y el vapor de agua debe difundirse a través de esta capa hacia la corriente de aire en movimiento. El calor se transfiere en sentido contrario.

\section{Velocidad óptima del flujo de aire}

Una circulación de aire demasiado alta reduce el espesor de esta capa estanca y, por consiguiente, reduce también la resistencia al flujo de vapor de agua hacia afuera, del flujo de calor al interior y la superficie húmeda; el secado es más rápido. Un flujo de aire elevado sustituye al aire húmedo frío más deprisa, acelerando además el secado. 
Con una corriente de aire débil hay dificultades en el secado de los ladrillos de la parte media del encañado a secar, en particular si el encañado es muy compacto. Sin embargo, con una corriente de aire elevada y continua, la velocidad de secado será muy alta, especialmente en los ladrillos externos del encañado.

El problema se ha solucionado con el sistema del flujo de aire intermitente a alta velocidad, mediante ventiladores en el secadero que impulsan chorros de aire y que están moviéndose continuamente ventilando las diferentes zonas del encañado. Estos sistemas se conocen con los nombres comerciales de unidades Rotomixair y Reciprojet (fig. 5). El chorro de aire ventila el aire humedo frío del interior del encañado; pero debido a que esto sucede en una parte pequeña del tiempo total de secado, la velocidad de secado global no es muy alta.

Otro principio es el del secado en húmedo. Como ha podido verse anteriormente, la parte exterior del ladrillo seca antes que la interior y reduce entonces tensiones que pueden provocar su rotura, particularmente con arcillas difíciles que tienen una estructura de poros muy finos, que impide la emigración del agua, dando lugar a diferencias de humedad importantes.

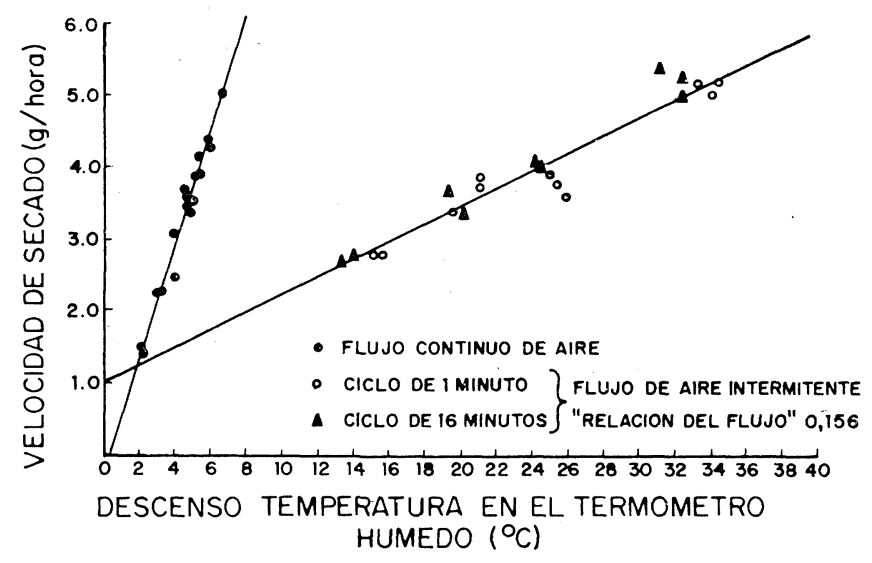

Fig. 5.-Efecto del flujo de aire intermitente sobre la velocidad de secado.

Frecuentemente no se considera necesario tener en cuenta la viscosidad del agua; pero con estructuras de poros muy finas llega a ser de importancia y, a semejanza del aceite por ejemplo, puede hacerse descender la viscosidad; es decir, si se aumenta la temperatura fluirá más fácilmente. Normalmente esto incrementará la velocidad de secado; pero si el aire circundante llega a ser tan húmedo que la evaporación es muy lenta, entonces el ladrillo y la humedad contenida en él pueden ser calentados con seguridad. Cuando se alcanza una alta temperatura, la humedad del aire desciende ligeramente mientras conserve la temperatura alta, y el secado se producirá bien sin que en el ladrillo se produzcan diferencias elevadas en el contenido de humedad.

Otro método para obtener los mismos resultados es caldear la arcilla antes de moldear los ladrillos calentando la mezcladora con vapor (templado con vapor). Esto tiene la ventaja adicional de ayudar a la desintegración y favorecer la plasticidad en los materiales duros esquistosos y puede suponer una economía hasta del $40 \%$ en la energía necesaria para la extrusión. El secado en húmedo y el templado con vapor, sin embargo, son sólo válidos en ciertas circunstancias y no se emplean mucho en Inglaterra. 
Recapitulando sobre el comportamiento al secado (fig. 6), éste se produce en dos etapas. A no ser que se intente hacer todo el secado en el horno, todos los ladrillos deben de encontrarse en la etapa dos antes de ser encañados. El encañado en húmedo de los ladrillos puede dar lugar a desechos debido a las grietas originadas por secado rápido, condensación e hinchamiento. Ladrillos agrietados y rotos pueden ser el resultado de un encañado desigual debido a la retracción variable por secado en el horno.

\section{ETAPA 1}

Contenido de humedad superior al $10 \%$. Gran retracción por secado.

Un secado demasiado rápido origina agrietamientos.

La velocidad de secado depende de:

Temperatura del aire.

Humedad del aire.

Velocidad del aire.

\section{ETAPA 2}

Contenido de humedad inferior al $10 \%$.

Pequeña retracción por secado.

Poca tendencia al agrietamiento.

La velocidad de secado depende de: Temperatura.

Densidad del ladrillo.

Fig. 6.-Comportamiento general al secado de la arcilla.

No siempre es necesario, e incluso puede ser desaconsejable, secar por completo los ladrillos antes de encañarlos en el horno. Puede resultar térmicamente ineficaz, y si se deja a los ladrillos almacenados durante un intervalo de tiempo apreciable antes de cocerlos reabsorberán humedad de la atmósfera. Con determinadas arcillas, esto puede dar lugar a finas grietas y pérdidas de resistencias.

\section{O C C I O N}

Un encañado desigual, con los correspondientes desechos, puede ser debido a una desigualdad en la solera del horno, que queda descuidada a veces durante largos períodos. En los hornos túnel un encañado desigual, debido a una variable retracción o a una solera desigual, da lugar en muchos casos a ruinas, con el consiguiente desperdicio y pérdidas de producción.

Un rápido calentamiento en el horno al comienzo de la cocción puede causar daños, incluso con ladrillos que tengan un contenido de humedad muy bajo; los ladrillos no están completamente secos hasta sobrepasar los $120^{\circ} \mathrm{C}$, e incluso los $200^{\circ} \mathrm{C}$, y durante un tiempo apreciable.

\section{Margen de seguridad para cubrir las variaciones}

Los experimentos nos han demostrado (fig. 7) que algunos ladrillos con un contenido de humedad del $2 \%$ se deterioraron cuando repentinamente se les sometió a una atmósfera de $250^{\circ} \mathrm{C}$, si bien otros pudieron resistir más de $400^{\circ} \mathrm{C}$ (fig. 8). Hubo considerables diferencias entre partidas de la misma producción. Se pudo apreciar que esto provenía de variaciones en la mezcla de arcilla o de variaciones en el tratamiento de secado. Las superficies del material extruido formaban espina de pez en una profundidad de hasta media pulgada $(12 \mathrm{~mm})$, en algunos con explosión perceptible por el oído, y en los casos peores puede darse el caso de que el desprendimiento llegue a tal extremo que quede sólo el núcleo central. Las caras formadas por cortadora de alambres no se desconchan, pero muestran la influencia de los planos de deslizamiento formados durante el proceso de extrusión. 


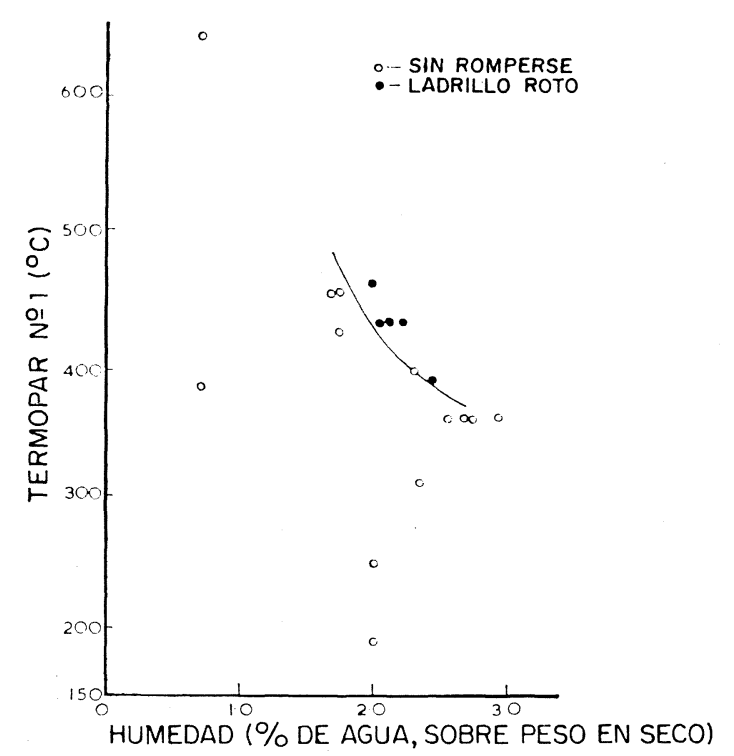

Fig. 7.-Desconchamiento de los ladrillos de $66,7 \mathrm{~mm}$.

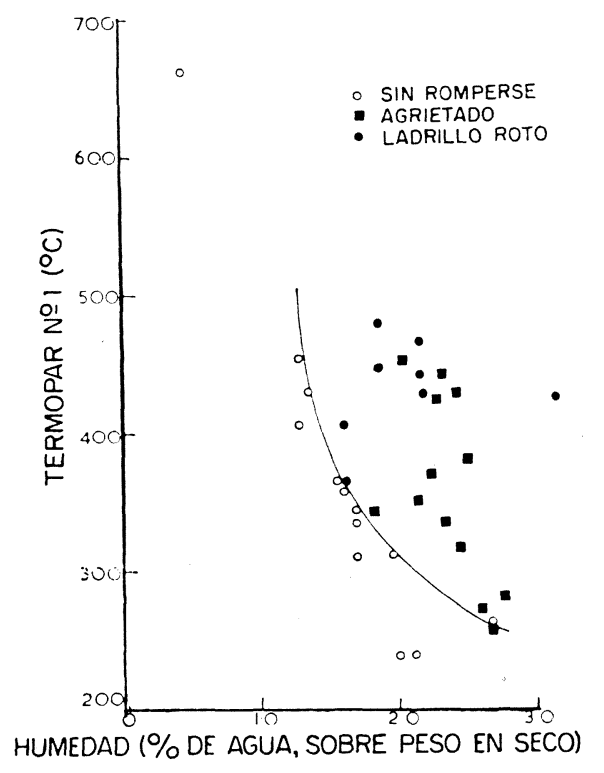

Fig. 8.-Desconchamiento de los ladrillos de $73 \mathrm{~mm}$.

Otro defecto, también de aspecto similar, parece estar originado por las diferencias de dilatación térmica como consecuencia del rápido calentamiento en las primeras etapas una vez que los ladrillos están completamente secos (fig. 9).
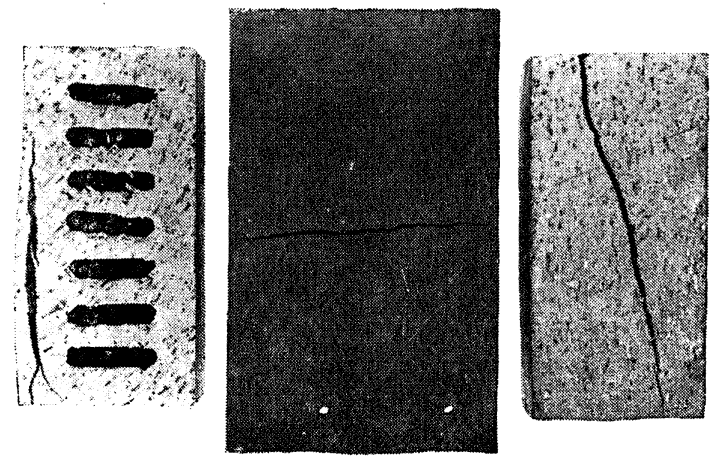

Fig. 9.-Agrietamientos debidos a una cocción demasiado rápida en las primeras etapas.

Antes se mencionó el hecho de que en el secado las superficies expuestas se secan y retraen primero. Cuando la parte interna tiende a retraerse posteriormente, esto viene restringido por las rígidas capas exteriores, formándose tensiones de compresión en la zona exterior y de tracción en la interior. Al cocer los ladrillos en el horno, estas tensiones tienden a incrementarse debido a la dilatación térmica $y$, si la velocidad de calentamiento es demasiado rápida, se producen las roturas tal como pueden verse en la figura 9 . La teja del centro se secó y coció en un apilamiento muy compacto y, de tal modo, que el secado y la cocción se produjo únicamente en la periferia. 
El ladrillo perforado se agrietó en un plano paralelo a la extrusión, y la capa externa se curvó siguiendo la compresión. En algunos casos esta grieta se extiende de extremo a extremo del ladrillo, en tanto que la capa externa queda retenida en el extremo opuesto. Después de la cocción, esta capa externa resultó ser apreciablemente más larga que el resto del ladrillo. La grieta que presenta el ladrillo macizo sigue probablemente un plano de debilitamiento originado por la boquilla extrusora.

Estos defectos se produjeron a diferentes temperaturas en ladrillos de distintas fábricas, y pudieron evitarse cociéndolos más despacio entre $550^{\circ}$ y $650^{\circ} \mathrm{C}$ ciertos ladrillos y entre $300^{\circ}$ y $800^{\circ} \mathrm{C}$, otros. En consecuencia, para darnos una idea del problema, la cocción lenta se realizó a $270^{\circ} \mathrm{C} /$ hora y $150^{\circ} \mathrm{C} /$ hora, respectivamente (figs. 16 y 17 ).

Las condiciones que causan las faltas mencionadas - sometiendo los ladrillos no totalmente secos a $250^{\circ} \mathrm{C}$ y calentándolos a $150^{\circ} \mathrm{C} /$ hora - deben ser tan severas que no sea probable que se presenten en la práctica. Sin embargo, las condiciones son algunas veces mucho más severas cuando se realizan sin instrumentación y medidas extensivas, y las faltas se producen; por ejemplo, debido a la flotabilidad de los gases en las hiladas más bajas de la zona de precalentamiento en una vagoneta de horno túnel, el encañado puede estar a una temperatura comparativamente más baja cuando entren en la zona de cocción, y circunstancias parecidas pueden darse en un horno de los del tipo Hoffmann.

Entre aproximadamente $450^{\circ}$ y $650^{\circ} \mathrm{C}$ los minerales arcillosos experimentan una alteración química y el agua es eliminada. Este agua alcanza hasta un $14 \%$ en una verdadera arcilla y alrededor de un $2 \frac{1}{2}$ a un $10 \%$ en un ladrillo de mezcla de arcillas. Una producción, por ejemplo, de 300.000 por semana, supone de 136 a 590 litros de agua/hora.

Este vapor de agua puede combinarse con los gases sulfurosos procedentes de la zona de cocción desprendidos del combustible o de la arcilla, y el ácido resultante puede condensarse sobre los ladrillos fríos que entran en la zona de precalentamiento, dando lugar a que se hinchen.

\section{Cambios químicos endotérmicos}

La rotura de la red cristalina de la arcilla es endotérmica, es decir, toma calor. Esto puede verse en la curva de análisis térmico diferencial (fig. 10). Una muestra de un material arcilloso molido y de un material inerte se colocan una al lado de otra en un horno de laboratorio que se calienta a una velocidad constante. El material inerte se calienta de una forma constante, pero la temperatura en la muestra de arcilla depende del calor absorbido o cedido por las reacciones químicas. Situando las diferencias de temperatura a través del ciclo de calentamiento, pueden observarse la sucesión y efecto de las diferentes reacciones. Similarmente, en un ladrillo la elevación de temperatura en el centro desciende hasta que se ha completado la reacción; y en la cocción rápida, esto puede dar lugar a considerables diferencias de temperatura entre el centro y la superficie (figs. 11, 12 y 13). En esta etapa el ladrillo es muy débil, pero afortunadamente la dilatación térmica cesa en este punto y el ladrillo empieza a contraerse. Las tensiones originadas por la diferencia de temperatura a través del ladrillo son mitigadas e, incluso, con velocidades de cocción muy rápidas no parece que produzcan daños en esta etapa. De hecho, puede ganarse tiempo, en un horno túnel, por ejemplo, incrementando la entrada de calor en la zona correspondiente. 


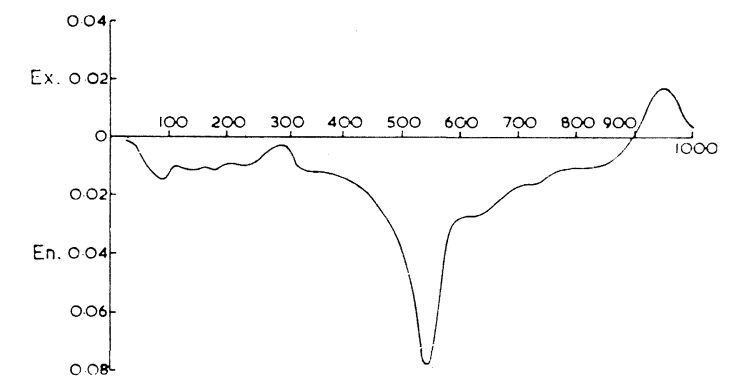

Fig. 10.-Curva de análisis térmico diferencial de una marga de Etruria.

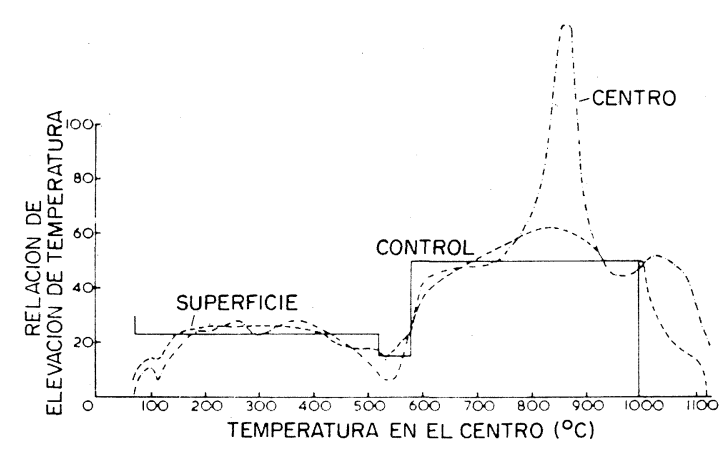

Fig. 12.-Velocidades de elevación de temperatura en el centro $y$ en la superficie en una teja durante una cocción rápida.

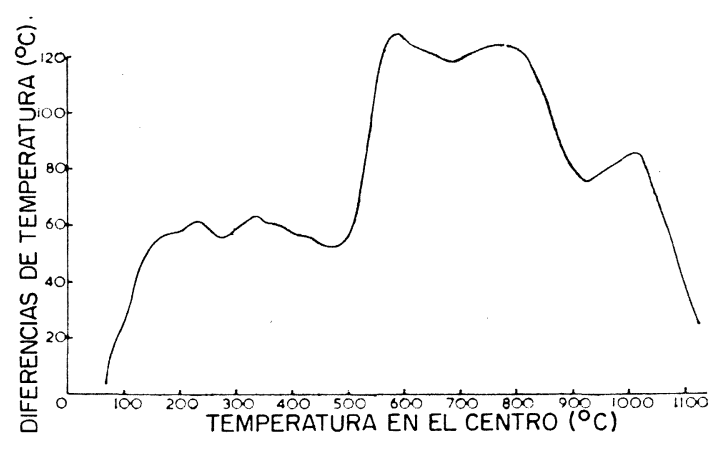

Fig. 11.-Diferencia de temperaturas entre el centro $y$ la superficie en la parte gruesa de una teja durante una cocción rápida.

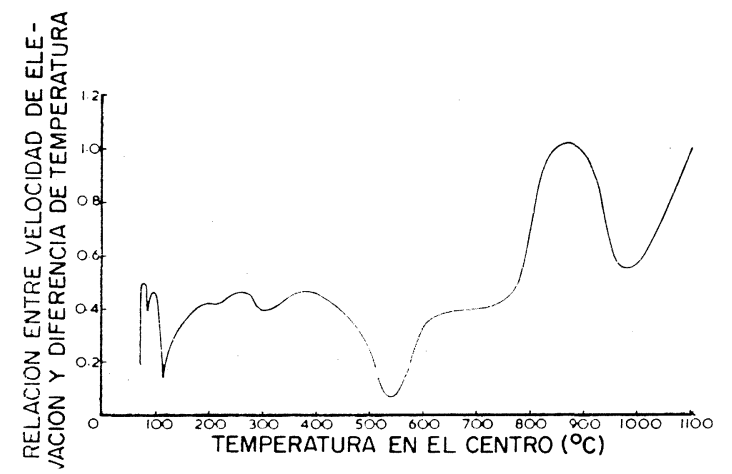

Fig. 13.-Relación entre velocidad de elevación de temperatura en el centro y la diferencia de temperatura en la parte gruesa de una teja, durante una cocción rápida.

Los retrasos en elevación de temperatura dan lugar a grandes diferencias de temperatura no solamente a través de todo el ladrillo, sino de todo el encañado. Cuando se ha completado la reacción en las partes más frías, esta alta diferencia de temperaturas provoca una elevación de temperaturas muy rápida. Esto no da lugar a daños físicos, pero puede afectar a la oxidación.

Se sabe que algunas arcillas para ladrillos pueden contener hasta $40 \%$ de materiales carbonosos; incluso 0,1 \% en las margas de Etruria pueden dar lugar a "corazón negro". Los hidrocarburos volátiles se destilan a partir de unos $350^{\circ} \mathrm{C}$, dentro de un cierto tiempo, pero dejan un residuo carbonoso que precisa una temperatura mucho más alta para oxidarse. El "corazón negro" no es en sí carbono, sino que está motivado por la reducción de los óxidos de hierro en la masa arcillosa por el carbono, y, posiblemente, por los sulfuros. El carbón arde y la reoxidación de la pasta se produce después de que se complete la etapa de rotura de la estructura de la arcilla y continúa hasta que la superficie llega a "cerrarse", restringiéndose la permeabilidad para que pase el oxígeno.

La oxidación se efectúa más deprisa a altas temperaturas antes de que se "cierre" la superficie (formación de vidrio en la superficie), generalmente a unos $850^{\circ} \mathrm{C}$ en la mayoría de las arcillas y a unos $1.000^{\circ} \mathrm{C}$ en las arcillas refractarias. Algunas arcillas requieren muchas horas dentro de una atmósfera oxidante, a la temperatura óptima, para eliminar el "corazón negro"; dependiendo esto de la permeabilidad de la masa y del contenido de carbono y azufre. Es necesario tener cuidado para evitar pasarse de la temperatura en la elevación rápida que sigue a la fase de rotura de la estructura de la arcilla y la resultante por entrar el carbón en combustión. 
En algunos casos se tiene la creencia de que el encañado de los ladrillos húmedos da lugar al "coraźón negro". Esto es debido a que los ladrillos no llegan a alcanzar una temperatura superior a los $100^{\circ} \mathrm{C}$ hasta que no se encuentran completamente secos, en cuyo tiempo la temperatura del horno generalmente tiene que ser incrementada muy por encima de la misma. Esto es muy similar a lo que sucede durante la rotura de la estructura cristalina de la arcilla, con resultados muy parecidos. La gran diferencia de temperaturas da lugar a que los ladrillos se calienten rápidamente y no tengan el tiempo que normalmente deberían poseer (alrededor de $300-400^{\circ} \mathrm{C}$ cuando los hidrocarburos se están eliminando por destilación). Con los ladrillos húmedos se precisa un tiempo extra durante el desprendimiento de vapor, o hasta el comienzo del precalentamiento, o hasta que se pueda evitar la formación de corazón negro, mediante una cocción más prolongada a unos $850^{\circ}-950^{\circ} \mathrm{C}$.

Después de la oxidación, la siguiente y última etapa de la cocción es la vitrificación, o sea, dar al ladrillo una buena resistencia mecánica y durabilidad a la intemperie. Esto viene afectado tanto por la temperatura como por el tiempo a dicha temperatura; pero la temperatura tiene un mayor efecto. Por ejemplo, para una arcilla con 2 horas y $1.200^{\circ} \mathrm{C}$ se obtienen mayores resistencias que con 12 horas y $1.150^{\circ} \mathrm{C}$. Si la temperatura de acabado es demasiado alta se afecta la coloración del ladrillo — normalmente resulta de color más oscuro- y suele tener más ampollas y granos debidos a las impurezas ricas en hierro; pero corrientemente la temperatura de acabado viene determinada por el comportamiento a la retracción y reblandecimiento.

Esto puede verse en las curvas de deformación bajo carga (figs. 14 y 15). Para ello se confeccionan probetas con la arcilla que se está estudiando y un corto número de éstas se colocan en un horno de laboratorio que aplica una determinada carga, como la que ha de soportar el ladrillo encañado en el horno. La temperatura se va incrementando a una velocidad constante y se registran las contracciones. Para conseguir las propiedades apetecibles es necesario, por regla general, que se produzca cierta retracción; pero si la temperatura de acabado es demasiado alta, entonces cabe esperar una amplia variación dimensional en los ladrillos.

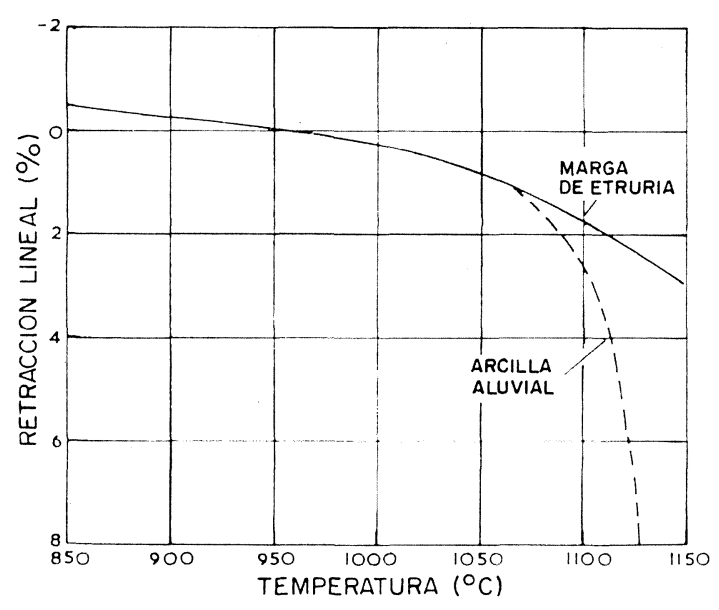

Fig. 14.-Efecto de la temperatura de cocción sobre la retracción de la probeta sometida a carga.

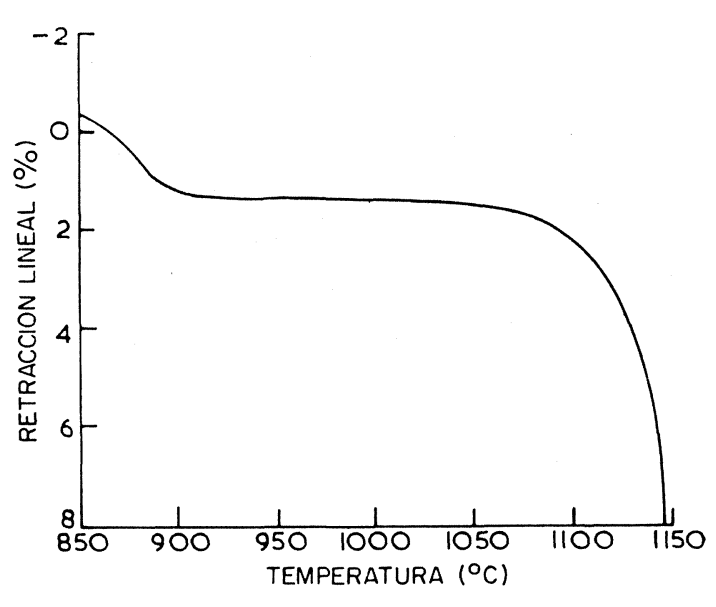

Fig. 15.-Efecto de la temperatura de cocción sobre una probeta de marga del Keuper sometida a deformación bajo carga. 
Aunque las propiedades de los ladrillos cocidos dependen principalmente de la temperatura de acabado, se requiere un tiempo adecuado en la cocción final para obtener la uniformidad de temperatura, necesaria para conseguir que el color, tamaño y otras propiedades sean suficientemente constantes. Para esto suelen ser de gran utilidad las barras Holdcroft, los anillos de Buller y las probetas de ensayos.

\section{E N F R I A M I E N T O}

Durante el enfriamiento el cuarzo experimenta un cambio físico a $570^{\circ} \mathrm{C}$ con una contracción de volumen del $2,4 \%$. Si la velocidad de enfriamiento es muy rápida en este punto, y si existe una gran proporción de arena en la masa, pueden formarse pequeñas fisuras alrededor de las partículas de cuarzo en cantidad suficiente para debilitar apreciablemente el ladrillo, que no tendrá en ese caso un buen sonido. De hecho, siempre hay presente algo de arena y los ladrillos son frecuentemente más débiles de lo que deberían ser, pero naturalmente son más fuertes de lo que es necesario en la práctica. Por regla general es difícil controlar la masa que se está enfriando a una determinada temperatura en todas sus partes en el encañado; sin embargo, los desperfectos raramente se producen durante el enfriamiento.

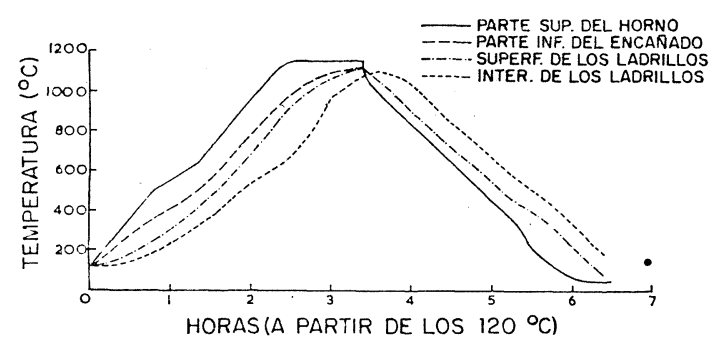

Fig. 16.-Cocción rápida (sỉn desperfectos) de unos ladrillos perforados hechos con marga de Etruria en la fábrica $\mathbf{A}$.

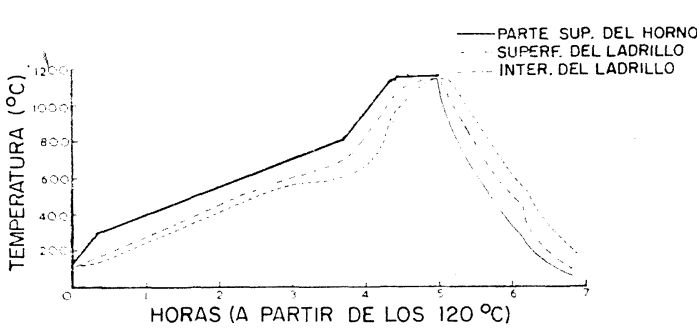

Fig. 17.-Cocción rápida $y$ sin desperfectos de los ladrillos macizos de $73 \mathrm{~mm}$, hechos con marga de Etruria en la fábrica $B$.

Muchos de los defectos mencionados se producen por una cocción demasiado rápida, pero de hecho los ladrillos fabricados con marga de Etruria procedentes de diversas factorías se han cocido y enfriado satisfactoriamente entre 6 y $6 \frac{1 / 2}{2}$ horas (figs. 16 y 17). Con estas altas velocidades de cocción se desecharon los "corazones negros", aunque, sin embargo, los contenidos de carbón de la arcilla fueron inferiores al $0,1 \%$. 